\title{
Graded concentrations of digestible lysine on performance of White Leghorn laying hens fed sub-optimal levels of protein
}

\author{
Venkata Rama Rao Savaram ${ }^{1}$,, Shyam Sundar Paul ${ }^{1}$, Venkata Lakshmi Narasimha Raju Mantina ${ }^{1}$, \\ Nagalakshmi Devanaboyina ${ }^{2}$, and Prakash Bhukya ${ }^{1}$
}

\section{* Corresponding Author: Venkata Rama Rao Savaram \\ Tel: +91-40-24017000, Fax: +91-24017002 \\ E-mail: svramarao1@gmail.com \\ ${ }^{1}$ ICAR-Directorate of Poultry Research, Rajendranagar, Hyderabad-500030, \\ Telangana, India \\ 2 College of Veterinary Science, PVNR \\ Telangana Veterinary University, Hyderabad 500030, India \\ ORCID \\ Venkata Rama Rao Savaram \\ https://orcid.org/0000-0002-2054-9055 Shyam Sundar Paul \\ https://orcid.org/0000-0002-9549-5741 Venkata Lakshmi Narasimha Raju Mantina https://orcid.org/0000-0001-5175-8784 \\ Nagalakshmi Devanaboyina \\ https://orcid.org/0000-0002-3630-8774 \\ Prakash Bhukya \\ https://orcid.org/0000-0003-1857-2464}

Submitted Jan 10, 2020; Revised Feb 15, 2020; Accepted Apr 10, 2020
Objective: An experiment was conducted to study the effect of graded concentration of digestible lysine (dLys) on performance of layers fed diets containing sub-optimal level of protein.

Methods: Five diets were formulated to contain graded concentrations of dLys $(0.700 \%$, $0.665 \%, 0.630 \%, 0.593 \%$, and $0.563 \%)$, but similar levels of crude protein ( $15 \% \mathrm{CP})$, energy $(10.25 \mathrm{MJ} \mathrm{ME} / \mathrm{kg}$ ) and other nutrients. A total of 3,520 hens (26 wk of age) with mean body weight of 1,215+12.65 g were randomly divided into 40 replicate groups of 88 birds in each and housed in an open sided colony cage house. Each diet was offered ad libitum to eight replicates from 27 to $74 \mathrm{wk}$ of age. The performance was compiled at every $28 \mathrm{~d}$ and the data for each parameter were grouped into three phases, that is early laying phase (27 to 38 wk), mid laying phase (39 to $58 \mathrm{wk}$ ), and late laying phase (59 to $74 \mathrm{wk}$ of age) for statistical analysis.

Results: Egg production, egg mass and feed efficiency (feed required to produce an egg) were significantly improved by the dLys level during the early and mid laying phases but not during the late phase. Whereas feed intake was significantly reduced by dLys concentration during mid and late laying phases but not during early laying phase. The egg weight was not affected by dLys concentration in any of the three phases.

Conclusion: Based on best fitted statistical models, dietary requirements of dLys worked out to be $0.685 \%, 0.640 \%$, and $0.586 \%$ during early phase, mid phase, and late egg laying phase, respectively. The calculated requirement of dLys for the respective production phases are $727 \mathrm{mg} / \mathrm{b} / \mathrm{d}$ during the early and mid laying phases and $684 \mathrm{mg} / \mathrm{b} / \mathrm{d}$ during the late laying phase in diets containing $15 \% \mathrm{CP}$.

Keywords: Egg Mass; Egg Production; Egg Weight Feed Efficiency; Layer; Lysine

\section{INTRODUCTION}

Utilization of dietary protein is higher at sub-optimal concentration of feeding and thus the excretion of nitrogen is proportionately less at lower dietary concentrations of crude protein (CP) [1]. Hence, with increased availability of synthetic amino acids (AA) at reasonable price, diet formulation with precise concentrations of AA and minimum level of protein were adopted to reduce cost and nitrogen excretion [2]. The AA requirements of laying hens are generally based on performance criteria. During past two decades, productivity, persistency of lay and feed efficiency (FE) of laying hens increased substantially while body weight (BW) has decreased. Therefore, the NRC [3] recommendations may not be accurate in predicting requirements of AA for current genotypes of laying hen. Most AA requirement studies on layers have been conducted during early $[4,5]$ or late production $[6,7]$ phases. Experiments conducted for short duration or part of production cycle 
may not truly represent the entire production cycle. Meluzzi et al [1] found that low CP (13\%) diet supplemented with AA sustained performance during the initial $8 \mathrm{wk}$ of the experiment, after which EP and egg mass (EM) decreased compared to those fed diets with the recommended CP level (17\%).

Establishment of precise AA requirements for different ages would allow full expression of the genetic potential throughout their laying phases besides creation of more precise, environment friendly and economical feeding program. The present experiment was conducted on White Leghorn (WL) layers of Babcock strain for almost full laying cycle i.e. from 27 to $74 \mathrm{wk}$ of age, to evaluate the effects of graded concentrations of digestible lysine (dLys) in low CP diet on the production performance and to determine their optimum dietary concentrations under tropical condition.

\section{MATERIALS AND METHODS}

\section{Birds and management}

Birds: The experiment was conducted by following the guidelines of the Institute Animal Ethical Committee (approval number IAEC/DPR/6/2015). A total of 3,520 commercial layers (26 wk of age) of Babcock strain with mean BW of $1,215+12.65 \mathrm{~g}$ were placed in 4 bird colony cages and 22 adjacent colony cages having a common feeder were considered as a replicate. Thus, all the birds were equally housed in 40 replicate groups. Eight replicates (88 birds in each) were assigned to each of the five treatments in a completely randomized design. The cages were placed in an open-sided poultry house fitted on an elevated platform. Fluorescent bulbs were used to provide $16 \mathrm{~h}$ light period daily, including the daylight. The average minimum and maximum temperatures in the house during the three production phases experiment were $23.2^{\circ} \mathrm{C} \pm 3.85^{\circ} \mathrm{C}$ and $37.5^{\circ} \mathrm{C} \pm 6.26^{\circ} \mathrm{C}$, respectively.

Diets: Five diets were formulated to contain graded concentrations of dLys $(0.700 \%, 0.665 \%, 0.630 \%, 0.593 \%$, and $0.563 \%)$, but similar levels of protein ( $15 \% \mathrm{CP})$, energy (10.25 $\mathrm{MJ} \mathrm{ME} / \mathrm{kg}$ ) and other nutrients. Diets were prepared utilizing maize, soybean meal, sunflower cake, rapeseed cake, and deoiled rice bran to meet the recommended nutrient levels as per the feeding standards of the strain used [8] except for protein and AA. All the feed ingredients were analysed [9] for total Lys (Lys), methionine (Met), threonine (Thr), and tryptophan (Try) at the beginning of the experiment, and also as and when a new consignment of feed ingredient was received for feed compounding. The digestible coefficients for the above AA as suggested by Evonik (SEA) PTE LTD (Asia South Ingredient Report 2017) for the respective ingredients were used to calculate the concentrations of digestible Lys (dLys), methionine (dMet), threonine (dThr), and tryptophan (dTry) in diets. The levels of maize, soybean meal, sunflower meal, DL-Met and L-Lys $\mathrm{HCl}$ were altered to achieve the desired concentration of AA in experimental diets. Each diet was offered ad libitum to eight replicates (88 birds/replicate) from 27 to $74 \mathrm{wk}$ of age.

Traits measured: Egg production (EP) was recorded twice daily from 27 to 74 wk of age. Feed intake (FI) and the quantity of feed consumed to produce a unit weight of egg (FE) were compiled at $28 \mathrm{~d}$ intervals (period). The average egg weight (EW) was recorded by weighing 60 randomly selected eggs per replicate during the last 3 days of each period. The EM was calculated by multiplying the average EW with the total number of eggs produced in each replicate and expressed as g per hen per period. The BW of the birds was recorded at the beginning ( $27 \mathrm{wk}$ of age) and at the end of the experiment ( $74 \mathrm{wk}$ of age). Number of birds died during experiment was recorded to calculate the livability.

\section{Statistical analysis}

The data for each parameter were grouped into three phases and statistical analysis was carried out separately for each of the three phases. Data were analysed by the method of analysis of contrast variables using the general linear model procedures on analysis of variance for repeated measures using the Greenhouse-Geisser adjusted univariate significance tests as described by Littell et al [10] using SPSS [11]. Differences were considered to be significant at $\mathrm{p}<0.05$, whereas a trend was considered to exist if $\mathrm{P}$ was between 0.05 to 0.10 . Sum of squares for the treatment effect due to dLys concentration was further separated using orthogonal contrasts into single degree of freedom comparisons that included linear, quadratic, cubic and order 4 components of the response to the dLys concentration. Contrast analysis using Helmert contrast (which compares each level except the last with mean of all subsequent concentration) was also carried out to compare concentration of dLys to find out plateau, if any. For response variables with no significant effect of dLys concentration, the lowest level of dLys used in the study was considered as adequate. For response variables with significant effect of dLys concentration, four mathematical models were used to estimate the optimal level of dLys inclusion in diets to maximize layer responses based on a gradient treatment structure [12]. The EP, EW, FI, and FE were selected as layer responses. Linear brokenline, quadratic broken line (QBL), and exponential models were estimated using a nonlinear procedure, whereas the quadratic polynomial (QP) regression model was estimated using a regression procedure [11]. Details of the statistical models used were as described earlier [13]. The dLys requirements estimates based on $95 \%$ of maximal response were considered as optimum requirement level. A model with highest coefficient of determination values and smallest sum of square of residuals was considered as the best fit model. 
Practical dLys requirements were calculated by averaging estimates across four variables (EP, FE, EW, and FI) as per the strategy adopted earlier [13]. Estimates of requirements of digestible sulfur AA (dSAA) were derived from dLys requirement estimates based on the actual average ratio of these AA to that of dLys in the present study.

\section{RESULTS}

Data on ingredient and nutrient composition of experimental diets has been presented in Table 1. ME, calcium and available $\mathrm{P}$ contents in diet of all the groups were comparable. Protein content of all the diets was about $15 \%$ which is considered adequate to meet requirement of nonessential AA (NRC [3]). The concentrations of dLys and dMet in soybean meal, sunflower cake, mustard cake, deoiled rice bran and maize were respectively $2.655 \%$ and $1.156 \% ; 0.451 \%$ and $0.937 \% ; 1.621 \%$ and $1.412 \% ; 0.727 \%$ and $0.716 \% ; 0.210 \%$ and $0.330 \%$. The diets contained graded concentration of limiting AA (LAA) in fixed ratio to dLys. The average digestible LAA ratio during the entire study was dMet 51.6\%, dSAA $87.9 \%$, dThr $75.5 \%$, and dThr $24.2 \%$ relative to dLys.
Dietary variation in dLys concentrations did not influence $(\mathrm{p}<0.05)$ the final BW of layers (Av. BW at 74th wk were 1,581 , $1,575,1,586,1,574$, and $1,575 \mathrm{~g}$ in groups fed $0.700 \%, 0.665 \%$, $0.630 \%, 0.593 \%$, and $0.563 \%$ dLys, respectively.

\section{Early laying}

EP and EM were significantly $(\mathrm{p}<0.05)$ increased by the increase in concentrations of dLys in diet (Table 2) and also varied between periods, but interaction between period and dLys was non-significant (Table 2). Increasing the concentration of dLys showed linear response on EP and EM. Helmert contrast of EP and EM data indicated that EP and EM varied significantly among periods with peak at period 2 (31 to 34 wk of age).

The FI was not significantly affected by dLys concentration but varied significantly among periods. FE was significantly $(\mathrm{p}<0.01)$ improved with the concentrations of dLys in diet and the periods (Table 2). Increasing the level of dLys showed quadratic effect on FE.

The EW was not affected by the variation in concentrations of dLys in diet (Table 2) but was influenced significantly by period. Helmert contrast of EW data indicated significant

Table 1. Ingredient and nutrient composition of diets with different concentrations of dLys

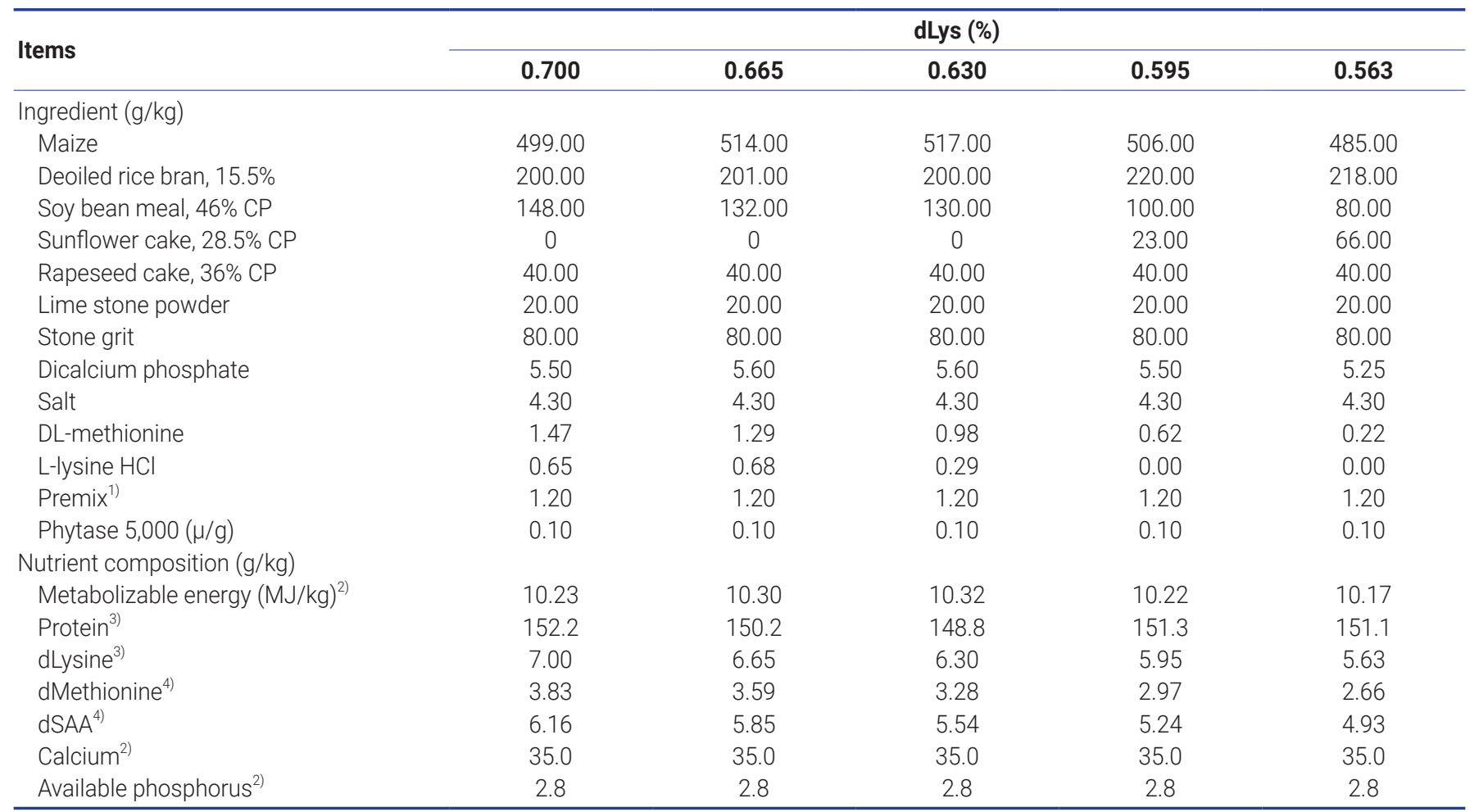

dLys, digestible lysine; CP, crude protein; dSAA, digestible sulfur amino acids.

1) Provided (mg/kg diet): thiamin 1; pyridoxine, 2; cyanocobalamine, 0.01; niacin, 15; pantothenic acid, 10; a tocopherol, 10; riboflavin, 10; biotin, 0.08; menadione, 2; retinol acetate, 2.75; cholecalciferol, 0.06; choline, 650; copper, 8; iron, 45; manganese, 80; zinc, 60; selenium, 0.18; hydrated sodium calcium alumino silicates, 800; phytase, 375 units.

2) Calculated.

3) Analyzed

4) Calculated based on analyzed ingredient composition. 
Table 2. Effect of graded concentrations of digestible lysine on various performance parameters in White Leghorn layers during first phase of laying (27 to 38 wk)

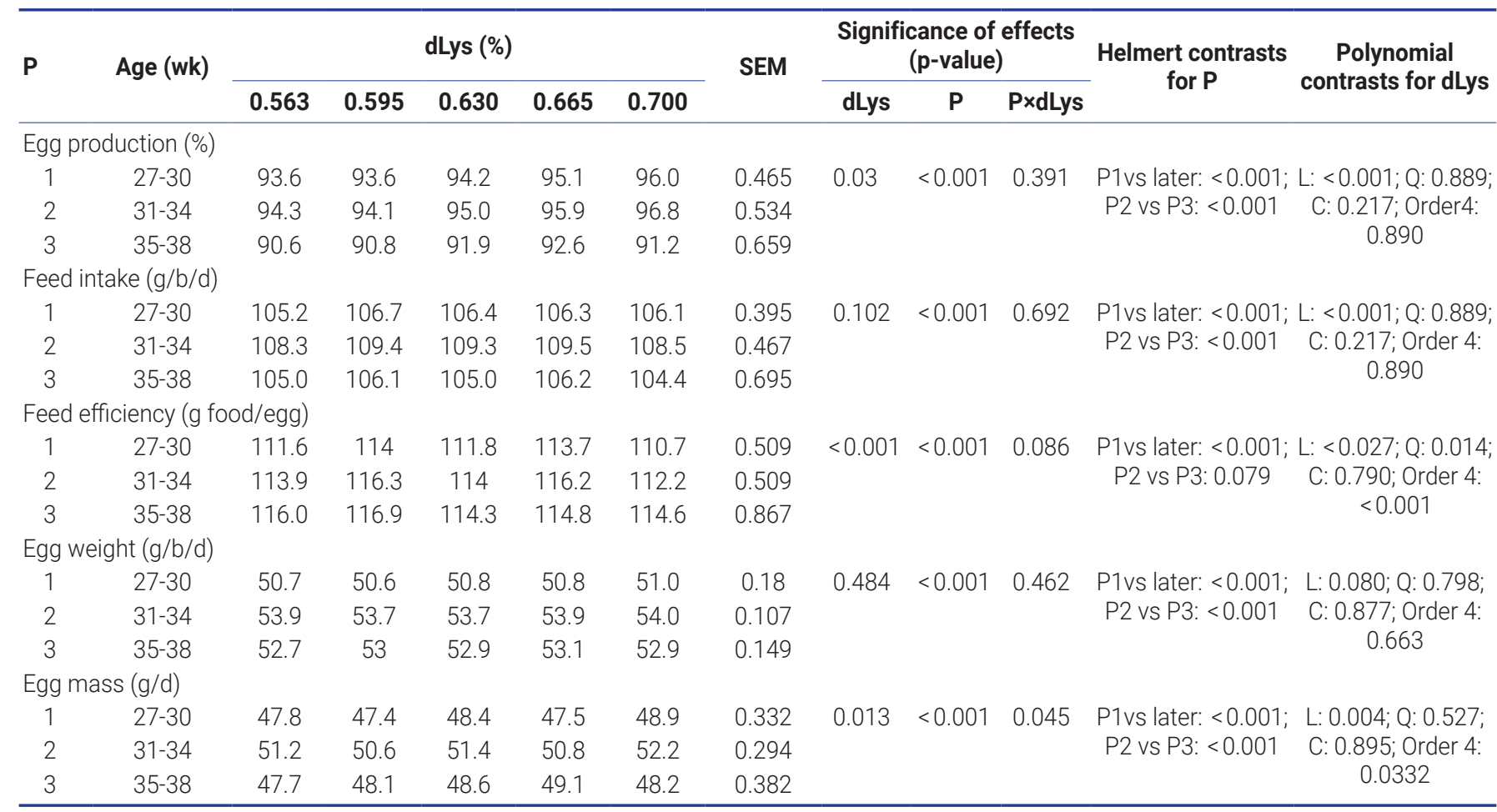

P, period; dLys, digestible lysine; SEM, standard error of the mean.

variation among periods.

These analyses indicated that the lowest dietary level of dLys used in the study ( $0.563 \%$ in diet) was adequate for optimal FI and EW responses. The dLys requirement estimates based on $100 \%$ and $95 \%$ of optimal responses for EP and FE were calculated from the mathematical model providing the best fit to the data set and have been shown in Table 6. In phase 1, for EP the best model (Exponential model) estimated dLys requirement (adequate for $95 \%$ of optimal response) at $0.815 \%$; for EM the best model (QBL) estimate was $0.660 \%$; for FE the best model (QP model) estimate was $0.581 \%$. On averaging values across responses where mathematical models were statistically significant (EP, EM, and FE), the dLys requirement (\% in diet) value during phase 1 works out to be $0.685 \%$.

\section{Mid laying}

EP and EM were significantly $(\mathrm{p}<0.05)$ increased with the concentrations of dLys in diet and also varied between periods, but interaction between period and dLys was non-significant (Table 3). Increasing the concentration of dLys showed significant quadratic response on EP and EM. Helmert contrast of EP or EM data indicated that EP or EM varied significantly among periods.

The FI was significantly $(\mathrm{p}<0.01)$ reduced by dLys concentration and also the periods. Increasing the concentration of dLys showed significant order 4 response on FI.

The FE was significantly $(\mathrm{p}<0.01)$ improved by the variation in concentrations of dLys in diet and also the periods (Table 4) but interaction between period and dLys concentration was non-significant. EW was not affected by the variation in concentrations of dLys in diet (Table 4) but was increased significantly with the age of the bird. Helmert contrast of EW data indicated significant variation among periods, except between period 4 and 5. The EW continued to increase with age of hen throughout the experiment.

These analyses indicated that the lowest dietary level of dLys used in the study $(0.563 \%$ in diet $)$ was adequate for optimal EW response. The dLys requirement estimates based on dLys intake for $100 \%$ and $95 \%$ of optimal responses for EP, FE, and FI were calculated from mathematical model providing best fit to the dataset and have been shown in Table 6. In phase 2, the best model (QP model) estimated dLys requirement ( $95 \%$ of optimal response) at $0.612 \%$; for EP, $0.665 \%$ for EM, $0.712 \%$ for FE, and $0.573 \%$ for FI. On averaging values across responses where mathematical models were statistically significant (EP, EM, FE, and FI), the dLys requirement for phase 2 has been worked out to be $0.640 \%$.

\section{Late laying}

$\mathrm{EP}$ and EM were not significantly $(\mathrm{p}>0.05)$ affected by the 
Table 3. Effect of graded concentrations of digestible lysine on egg production, feed intake and feed efficiency in White Leghorn layers during second phase of laying (39 to $58 \mathrm{wk}$ )

\begin{tabular}{|c|c|c|c|c|c|c|c|c|c|c|c|c|c|c|c|}
\hline \multirow{2}{*}{$\frac{\text { Items }}{\text { Period }}$} & \multicolumn{5}{|c|}{ Egg production (\%) } & \multicolumn{5}{|c|}{ Feed intake $(\mathrm{g} / \mathrm{b} / \mathrm{d})$} & \multicolumn{5}{|c|}{ Feed efficiency ( $\mathrm{g}$ food/egg) } \\
\hline & 1 & 2 & 3 & 4 & 5 & 1 & 2 & 3 & 4 & 5 & 1 & 2 & 3 & 4 & 5 \\
\hline Age (wk) & $39-42$ & $43-46$ & $47-50$ & $51-54$ & $55-58$ & $39-42$ & $43-46$ & $47-50$ & $51-54$ & $55-58$ & $39-42$ & $43-46$ & $47-50$ & $51-54$ & $55-58$ \\
\hline \multicolumn{16}{|l|}{ d Lys (\%) } \\
\hline 0.595 & 88.7 & 92.3 & 90.9 & 89.8 & 87.4 & 111.8 & 116.5 & 119.3 & 125.6 & 121.6 & 124.0 & 126.2 & 133.2 & 139.9 & 139.0 \\
\hline 0.630 & 90.1 & 91.9 & 90.4 & 89.8 & 88.0 & 107.0 & 114.2 & 115.0 & 122.9 & 118.7 & 120.6 & 124.2 & 127.3 & 136.9 & 134.8 \\
\hline SEM & 0.605 & 0.698 & 0.875 & 0.998 & 0.874 & 1.31 & 1.05 & 1.21 & 1.26 & 1.32 & 1.11 & 0.982 & 1.52 & 1.49 & 1.40 \\
\hline \multicolumn{16}{|c|}{ Significance of effects (p-value) } \\
\hline d Lys & \multicolumn{5}{|c|}{0.021} & \multicolumn{5}{|c|}{0.007} & \multicolumn{5}{|c|}{0.002} \\
\hline Period & \multicolumn{5}{|c|}{$<0.0001$} & \multicolumn{5}{|c|}{$<0.0001$} & \multicolumn{5}{|c|}{$<0.0001$} \\
\hline d Lys $\times$ Period & \multicolumn{5}{|c|}{0.631} & \multicolumn{5}{|c|}{0.709} & \multicolumn{5}{|c|}{0.862} \\
\hline $\begin{array}{l}\text { Helmert contrasts } \\
\text { for periods }\end{array}$ & \multicolumn{5}{|c|}{$\begin{array}{l}\text { P1vs later:0.050; P2 vs later:<0.001; } \\
\text { P3 vs later:<0.001; P4 vs P5:0.001 }\end{array}$} & \multicolumn{5}{|c|}{$\begin{array}{l}\text { P1vs later:<0.001; P2 vs later:<0.001; } \\
\text { P3 vs later:<0.001; P4 vs P5:<0.001 }\end{array}$} & \multicolumn{5}{|c|}{$\begin{array}{l}\text { P1vs later: }<0.001 ; \text { P2 vs later: }<0.001 \\
\text { P3 vs later:<0.001; P4 vs P5:0.053 }\end{array}$} \\
\hline
\end{tabular}

dLys, digestible lysine; FE, feed efficiency; SEM, standard error of the mean.

Table 4. Effect of graded concentrations of digestible lysine on egg weight in White Leghorn laying hens during second phase of laying (39 to 58 wk)

\begin{tabular}{|c|c|c|c|c|c|c|c|c|c|c|}
\hline \multirow{2}{*}{$\frac{\text { Items }}{P}$} & \multicolumn{5}{|c|}{ Egg weight (g/b/d) } & \multicolumn{5}{|c|}{ Egg mass $(g / b / d)$} \\
\hline & 1 & 2 & 3 & 4 & 5 & 1 & 2 & 3 & 4 & 5 \\
\hline Age (wk) & $39-42$ & $43-46$ & $47-50$ & $51-54$ & $55-58$ & $39-42$ & $43-46$ & $47-50$ & $51-54$ & $55-58$ \\
\hline \multicolumn{11}{|l|}{ dLys (\%) } \\
\hline 0.595 & 53.5 & 55.1 & 55.9 & 57.5 & 57.9 & 48.2 & 50.9 & 50.8 & 51.6 & 50.6 \\
\hline 0.630 & 53.6 & 54.9 & 55.8 & 57.6 & 57.9 & 47.6 & 50.5 & 50.5 & 51.7 & 50.9 \\
\hline SEM & 0.147 & 0.082 & 0.141 & 0.124 & 0.326 & 0.372 & 0.379 & 0.486 & 0.585 & 0.621 \\
\hline \multicolumn{11}{|c|}{ Significance of effects (p-value) } \\
\hline dLys & \multicolumn{5}{|c|}{0.925} & \multicolumn{5}{|c|}{0.034} \\
\hline $\mathrm{P}$ & \multicolumn{5}{|c|}{$<0.001$} & \multicolumn{5}{|c|}{$<0.001$} \\
\hline dLys $\times P$ & \multicolumn{5}{|c|}{0.863} & \multicolumn{5}{|c|}{0.639} \\
\hline
\end{tabular}

dLys, digestible lysine; P, period; SEM, standard error of the mean; HC, Helmert contrast; PC, polynomial contrast.

variation in concentrations of dLys in diet (Table 5). The EP was significantly $(\mathrm{p}<0.01)$ reduced with the age, but interaction between period and dLys was non-significant (Table 5). Helmert contrast of EP or EM data indicated EP or EM varied significantly among periods with a gradual declining trend with each passing period.

The FI was significantly $(\mathrm{p}<0.05)$ and quadratically reduced by dLys concentration and varied significantly among periods. FE was not significantly ( $p>0.05$ ) affected by the variation in concentrations of dLys in diet but varied among periods (Table 5). Increasing the concentration of dLys showed order 4 effect on FE.
The EW was not affected by the variation in concentrations of dLys in diet (Table 6) but was significantly increased with advancement of the bird age. Helmert contrast of EW data indicated significant variation among periods and indicated a gradual increase in EW with increasing age.

These analyses indicated that the lowest dietary level of dLys used in the study $(0.563 \%)$ was adequate for optimal EP, FE, and EW responses. The dLys requirement estimates based on $100 \%$ and $95 \%$ of optimal responses in FI were calculated from the best fitted mathematical model and have been shown in Table 5. In phase 3, for FI, the best model (exponential model) estimated dLys requirement (95\% of 
Table 5. Effect of graded concentrations of digestible lysine on performance parameters in White Leghorn laying hens during third phase of laying (59 to 74 wk)

\begin{tabular}{|c|c|c|c|c|c|c|c|c|c|c|c|}
\hline \multirow{2}{*}{$\mathbf{P}^{1)}$} & \multicolumn{5}{|c|}{ dLys (\%) } & \multirow[t]{2}{*}{ SEM } & \multicolumn{3}{|c|}{ Significance of effects ( $p$-value) } & \multirow{2}{*}{$\begin{array}{l}\text { Helmert contrasts } \\
\text { for } P\end{array}$} & \multirow{2}{*}{$\begin{array}{c}\text { Polynomial } \\
\text { contrasts for dLys }\end{array}$} \\
\hline & 0.563 & 0.595 & 0.630 & 0.665 & 0.700 & & dLys & $\mathbf{P}$ & PxdLys & & \\
\hline \multicolumn{12}{|c|}{ Egg production (\%) } \\
\hline 2 & 83.0 & 82.0 & 84.2 & 83.2 & 83.0 & 1.09 & & & & \multirow{3}{*}{\multicolumn{2}{|c|}{$\begin{array}{l}\text { P1 vs later: <0.001; } \\
\text { P2 vs later: <0.001; } \\
\text { P3 vs P4: <0.001 }\end{array}$}} \\
\hline 3 & 81.1 & 81.6 & 81.9 & 82.6 & 81.6 & 0.456 & & & & & \\
\hline 4 & 77.0 & 77.5 & 77.9 & 78.5 & 77.5 & 0.433 & & & & & \\
\hline 2 & 111.2 & 111.1 & 111.3 & 111.6 & 110 & 1.45 & & & & \multirow{3}{*}{$\begin{array}{l}\text { P1 vs later:0.362; } \\
\text { P2 vs later: <0.001; } \\
\text { P3 vs P4: <0.001 }\end{array}$} & \multirow{3}{*}{$\begin{array}{l}\text { L: 0.230; Q: 0.080; } \\
\text { C: 0.355; O 4: } 0.017\end{array}$} \\
\hline 3 & 115.5 & 116.9 & 114.6 & 117.2 & 113.5 & 0.761 & & & & & \\
\hline 4 & 117.9 & 119.3 & 117 & 119.6 & 115.8 & 0.776 & & & & & \\
\hline \multicolumn{12}{|c|}{ Feed efficiency (g food/egg) } \\
\hline 1 & 135.3 & 136.6 & 133.2 & 137.7 & 132.6 & 3.13 & 0.100 & $<0.001$ & 0.791 & $\begin{array}{l}\text { P1 vs later } 0.524 \\
\text { P2 vs later: } 0.871 \\
\text { P3 vs P4: } 0.006\end{array}$ & $\begin{array}{c}\mathrm{L}: 0.105 ; \mathrm{Q}: 0.581 \\
\mathrm{C:} 0.733 ; 0 \text { 4: } 0.025\end{array}$ \\
\hline 1 & 57.8 & 58.1 & 58 & 58.5 & 58.2 & 0.383 & 0.354 & $<0.001$ & 0.852 & \multirow{4}{*}{$\begin{array}{l}\text { P1 vs later: 0.015; } \\
\text { P2 vs later: <0.001; } \\
\text { P3 vs P4: <0.001 }\end{array}$} & \multirow{4}{*}{$\begin{array}{l}\text { L: 0.371; Q: } 0.160 \\
\text { C: } 0.718 ; 0 \text {;: } 0.239\end{array}$} \\
\hline 2 & 56.4 & 56.7 & 56.6 & 56.8 & 56.3 & 0.161 & & & & & \\
\hline 3 & 58.0 & 58.1 & 58.1 & 58.2 & 58.1 & 0.075 & & & & & \\
\hline 4 & 60.9 & 61.0 & 61.0 & 61.1 & 61.0 & 0.079 & & & & & \\
\hline \multicolumn{12}{|c|}{ Egg mass $(g / d)$} \\
\hline 1 & 49.0 & 50.2 & 49.6 & 50.3 & 49.0 & 0.677 & 0.425 & $<0.001$ & 0.607 & \multirow{4}{*}{$\begin{array}{l}\text { P1 vs later: <0.001; } \\
\text { P2 vs later: } 0.072 ; \\
\text { P3 vs P4: < } 0.001\end{array}$} & \multirow{4}{*}{$\begin{array}{c}\text { L: } 0.522 ; \\
\text { Q:0.104;C:0.495; O } \\
4: 0.641\end{array}$} \\
\hline 2 & 46.8 & 46.6 & 47.7 & 47.2 & 46.7 & 0.628 & & & & & \\
\hline 3 & 47.0 & 47.4 & 47.6 & 48.0 & 47.4 & 0.267 & & & & & \\
\hline 4 & 46.9 & 47.3 & 47.5 & 47.9 & 47.2 & 0.285 & & & & & \\
\hline
\end{tabular}

dLys, digestible lysine; SEM, standard error of the mean; L, linear; Q, quadratic; C, cubic; 04 , order 4.

1) P, period (1, 59 to $62 \mathrm{wks} ; 2,63$ to $66 \mathrm{wks} ; 3,67$ to $70 \mathrm{wks} ; 4,71$ to $74 \mathrm{wks}$ ).

optimal response) at $0.586 \%$. On averaging values across responses where mathematical models were statistically significant (FI), the dLys requirement (\% in diet) values for phase 3 works out to be $0.586 \%$.

\section{DISCUSSION}

Among the AA requirements, Lys is especially important because it is used as the basis for setting the requirements for all other AA [2,14]. Multiple factors like basal diet, genetic lines, ambient temperature, age, carry over effect of previous concentration of AAs, etc. influence AA requirements [15]. Most of the earlier experiments on AA requirements of WL hens have been conducted for shorter duration. Here we

Table 6. Requirements of dLys for laying hens fed diet containing graded concentrations of dLys during different phases

\begin{tabular}{|c|c|c|c|c|c|c|}
\hline Response variable & Model & Equation & $\begin{array}{c}\text { Estimated requirement } \\
(100 \%, 95 \%)\end{array}$ & $\begin{array}{c}\text { Sum of square of } \\
\text { residuals }\end{array}$ & p-value & $\mathbf{R}^{2}$ \\
\hline \multicolumn{7}{|l|}{ Phase1 (27 to 38 wk) } \\
\hline Egg mass & QBL & $Y=49.3-28.74 \times(0.695-X)^{2}$ & $0.695,0.660$ & 14.25 & $<0.01$ & 0.212 \\
\hline Feed efficiency & QP & $Y=18.56+314.6-257.2 X^{2}$ & $0.612,0.581$ & 87.4 & $<0.01$ & 0.179 \\
\hline \multicolumn{7}{|l|}{ Phase 2 (39 to 58 wk) } \\
\hline Feed efficiency & QP & $Y=202.2-197.9 X+132.4 X^{2}$ & $0.747,0.709$ & 211.8 & $<0.01$ & 0.295 \\
\hline Feed intake & QP & $Y=8.29+364.1 X-301.8 X^{2}$ & $0.603,0.573$ & 386.6 & $<0.01$ & 0.092 \\
\hline \multicolumn{7}{|l|}{ Phase 3 (59 to 74 wk) } \\
\hline Feed intake & QP & $Y=-27.3+463.9 X-375.7 X^{2}$ & $0.617,0.586$ & 287.0 & $<0.01$ & 0.092 \\
\hline
\end{tabular}

dLys, digestible lysine; E, exponential; QP, quadratic polynomial; $Q B L$, quadratic broken line. 
have covered almost full laying cycle. Further there is a need to recommend the requirement of Lys for each production phase which vary in BW, EW and level of production. In this study we have attempted to estimate AA requirements for early, mid and late laying cycle separately to have more precise estimates. The interaction between dLys concentration and the period is clearly evident in present data. The effect of period represents the hen's age. With advancing age, egg size increases, the interval between ovulation increases causing deposition of same amount of yolk in smaller number of follicles influencing weight and size of eggs [14]. Data on digestible AA requirements of WL hens for different laying phases under tropical condition is scanty. In the present study, it was assumed that dLys requirements will be between $0.700 \%$ to $0.563 \%$ during different phases of EP. The estimated requirements of dLys were $0.698 \%, 0.631 \%$, and $0.586 \%$, respectively during early, mid and late laying phases.

In early laying phase, based on the estimates of optimal dietary dLys concentrations and observed FI, daily intake of dLys was calculated to be $727 \mathrm{mg} / \mathrm{b}$. In mid laying phase, daily intake requirements of dLys were similar to that of early laying phase. In late laying phase daily intake requirements were worked out to be $684 \mathrm{mg} / \mathrm{b} / \mathrm{d}$. The NRC [3] recommends a total Lys consumption of $690 \mathrm{mg} / \mathrm{b} / \mathrm{d}$ to maximize $\mathrm{EM}$, corresponding to $593 \mathrm{mg} / \mathrm{b} / \mathrm{d}$ of true digestible Lys when applying a mean true Lys digestibility of $86 \%$ in corn and soybean meal based diet [3]. Bonekamp et al [16] and Spangler et al [17] reported that for Lohman LSL hens (light weight type), 600 to $620 \mathrm{mg} / \mathrm{b} / \mathrm{d}$ dLys intake was sufficient for optimal laying percentage during early to mid laying phase. However, they observed that optimal Lys intake for maximum EW and FE were higher than the requirement for EP. Earlier, Rama Rao et al [18] estimated total Lys and Met requirements of WL layers (Babcock) from 21 to $72 \mathrm{wk}$ of age in two trials involving supplementation of low CP ( $14.11 \%$ to $16.34 \% \mathrm{CP}$ ) high metabolizable energy (ME, $10.88 \mathrm{MJ} / \mathrm{kg})$ diets with graded concentration of Lys $(0.65 \%$ to $0.80 \%$ ) and reported that these layers require $0.7 \%$ lysine in diets containing approximately $15 \% \mathrm{CP}$ and $10.88 \mathrm{MJ}$ of $\mathrm{ME} / \mathrm{kg}$ but to achieve optimal EW a level of $16.5 \% \mathrm{CP}$ is required. Our current estimates are considerably higher than those of our previous findings [18]. Similarly, the optimum concentration of dLys observed in the current study are considerably higher than the concentration reported by some other researchers [ 5 dLys, 526 to $561 \mathrm{mg} / \mathrm{b} / \mathrm{d}$ ) for layers of similar age. Similar to the data of the present experiment, few studies [19-21] have reported higher Lys (752 to 876 $\mathrm{mg} / \mathrm{b} / \mathrm{d}$ ) requirement during the initial production phase. The relatively higher requirements of the dLys observed in the present study compared to some of the earlier reports may partly be attributed to higher rate of production ( $95 \%$ vs $83 \%$ to $89 \%$ ) and also FI ( $106 \mathrm{~g}$ vs $88.7 \mathrm{~g}$ to $100 \mathrm{~g} / \mathrm{b} / \mathrm{d}$ ) in the present study. The higher FI might have resulted in higher intake of these LAA in the current study compared to the reported values. The higher FI could be due to low energy concentration in diet of the present study $(10.25 \mathrm{MJ} / \mathrm{kg})$ compared to the dietary energy concentrations used by above authors (11.88 to $12.13 \mathrm{MJ} / \mathrm{kg}$ ). The FI during the initial 2 periods was not affected by the AA concentration in diet. Another probable reason for higher dLys requirements suggested by Santos et al [20] and Pastore et al [21] could be due to strain variation (Isa Browen and Hy-Line W36) which are heavy in BW compared to the strain used in the current study.

The optimum requirement of Lys also depends on the protein content in the test diets as observed in our earlier studies [22]. Higher Lys (598 vs $584 \mathrm{mg} / \mathrm{b} / \mathrm{d}$ ) requirement was observed when the layers fed low protein diet (13.36\% $\mathrm{CP})$ compared to those fed optimum protein (15.78\%).

The quantity of feed required to produce a unit egg reduced significantly with increase in dietary concentrations of dLys. Similarly, improvement in FE with increasing concentrations of Lys [17,23], Met, or total sulfur AA (TSAA) [24] in layers during post peak production was reported in the literature.

Majority of production parameters (EP, EW, and FE) were not affected by concentrations of dLys suggesting that the lowest level, i.e. $0.563 \%$ of dLys was adequate for these parameters. However, the FI was significantly reduced by dLys level. The daily intake requirements of dLys, during this phase works out to be $674 \mathrm{mg} / \mathrm{b}$, respectively. These correspond to intake requirement of $783 \mathrm{mg} / \mathrm{b} / \mathrm{d}$ total Lys when applying a mean true Lys digestibility of $86 \%$ in corn and soybean meal diet. The derived daily intake requirements of total Lys is similar to the values of total Lys ( 715 to $816 \mathrm{mg} / \mathrm{b} / \mathrm{d}$ ) requirements for layers reported by Novak et al [24] during mid to late laying phase. On the contrary, several authors have reported lower requirements of dLys [5, 561 to $526 ; 26,538$ to $561 ; 17$, $600 \mathrm{mg} / \mathrm{b} / \mathrm{d}$ ) compared to the intake requirement observed in the current study. The variation in the AA requirement might be due to the differences in CP level tested by various authors. Lower concentration of Lys (561 vs $526 \mathrm{mg} / \mathrm{b} / \mathrm{d}$ ) requirements were reported for optimum EP [5] with reduction in dietary CP from $14.3 \%$ to $13.65 \%$. Similarly, improvement in EP, EM, and FE were observed in layers (45 to 56 weeks of age) fed diets with $0.7 \%$ total lysine [6] with a calculated intake of $558 \mathrm{mg}$ dLys/b/d which is considerably lower than the values observed in the current study. The lower EP (56.2\%) observed in their study could be the reasons for the lower dLys requirements suggested by the authors.

Earlier, for the entire production or post peak phase (45 to 53 or 24 to $60 \mathrm{wk}$ of age, respectively), Bonekamp et al [16] and Harms and Russell [25] did not observe any difference 
in EP by reducing concentrations of Lys ( 800 to $550 \mathrm{mg} / \mathrm{b} / \mathrm{d}$ ) in diet. The calculated mean daily intake of dLys in these studies was $600 \mathrm{mg} / \mathrm{bird}$, which was marginally lower than the concentration observed in the present study $(674 \mathrm{mg} / \mathrm{b} / \mathrm{d})$. The lower requirements suggested by these authors may be due to use of lower concentrations of AA in relation to the higher levels of ME (11.72 and $12.13 \mathrm{MJ} / \mathrm{kg}$ ) in diet, which consequently reduced the average daily FI (110 and $88.7 \mathrm{~g} / \mathrm{b} / \mathrm{d}$ vs $115 \mathrm{~g} / \mathrm{b} / \mathrm{d}$ ) and intake of the AA in their studies.

The BW was not affected by increasing concentration of LAA in diet, which is contrary to our previous report [18], wherein BW increased significantly with increase in dietary Lys from $0.65 \%$ to $0.70 \%$ in diet and further increase in Lys to $0.75 \%$ did not improve the BW indicating that the optimum requirement of total Lys for BW gain in WL layers is about $0.70 \%$. The minimum level of dLys used in the present study $(0.563 \%)$ correspond to total Lys level of $0.65 \%$ which is nearer to the optimum Lys concentration $(0.70 \%)$ suggested in our earlier study [18]. Similar to the present findings, Sohail et al [26] did not observe any difference in BW in layers fed higher concentrations of SAA $(0.65 \%, 0.72 \%$, or $0.81 \%)$.

Considering the FI and performance data, the calculated daily intake of digestible TSAA works out to be $651 \mathrm{mg} / \mathrm{b}$ in the current study. Similarly, Rama Rao et al [18] estimated total TSAA requirements of WL layers (Babcock, Venkateswara Hatcheries Pvt Ltd, Pune, India) from 21 to $72 \mathrm{wk}$ of age and found optimum EP and BW at an intake of $532 \mathrm{mg} / \mathrm{b} / \mathrm{d}$, which is considerably lower than the values found in the current study. The higher requirements observed in the current study could be due to inclusion of sunflower meal and rapeseed meal in addition to higher levels of deoiled rice bran in the test diets. In our previous study [18] soybean meal was the primary source of protein whose digestibility is known to be higher than the alternate feed ingredients [27]. Similar to these observations, our recent study [13] also found higher requirements of TSAA ( 575 to $681 \mathrm{mg} / \mathrm{b} / \mathrm{d}$ ) for WL layers fed diets with less digestible protein source (guar meal 10\%) compared to those fed the soybean meal based diets (502 to $572 \mathrm{mg} / \mathrm{b} / \mathrm{d}$ ).

The EP realized in the current study was about $2 \%$ to $4 \%$ lower at different phases of production than the standard suggested (BV 300 layer management guide, Venkateswara Hatcheries Pvt Ltd, India). Similarly, the EW was about 2 to $5 \mathrm{~g}$ lower during the early phase of production but the difference reduced to 1 to $2 \mathrm{~g}$ in the late phase of EP. The lower production observed in the current study could be due to lower FI ( 1 to $6 \mathrm{~g} / \mathrm{b} / \mathrm{d})$ than the suggested in the manual. However, the requirement of dLys in the current study was higher than the levels recommended for the strain tested.

The EW was not affected by the variation in concentrations of dLys tested in the present study. Contrary to these findings, few authors $[16,25,28]$ have reported increased egg size with increases in intake or concentration of Lys, Met, Thr, or Try in diet. The variation in response of EW between the current experiment and that reported in literature may be due to the variation in concentration of the LAA. The above authors studied the response of supplementing a single AA in diets containing adequate concentration of other $\mathrm{AA}$ from deficit to high concentration. Supplementation of the most LAA in their studies might have improved EW. Some of these authors used diets containing unusual feed ingredients and supplemented the diet with essential AA in crystalline form to create deficiency of the specific AA studied. While in the current study, diets were prepared with practical feed ingredients and the concentration of Lys, Thr, and Try in the lowest dLys diets $(0.563 \%, 0.464 \%$, and $0.151 \%$, respectively) were higher than the adequate level [3] without supplementing crystalline AA.

\section{CONCLUSION}

The study indicated that WL layers require $727 \mathrm{mg} / \mathrm{b} / \mathrm{d}$ of dLys during the initial ( 27 to $38 \mathrm{wk}$ ) and mid ( 39 to $58 \mathrm{wk}$ ) production phase, while during the late laying phase (59 to $74 \mathrm{wk}$ ) an intake of $684 \mathrm{mg} / \mathrm{b} / \mathrm{d}$ was found optimum for EP, FE, FI, and EW when the diet contained $15 \%$ protein and about $10.25 \mathrm{MJ} / \mathrm{kg} \mathrm{ME}$.

\section{CONFLICT OF INTEREST}

We certify that there is no conflict of interest with any financial organization regarding the material discussed in the manuscript.

\section{ACKNOWLEDGMENTS}

Authors wish to express their sincere thanks to Mr C V Rao, Chalimeda Feeds Pvt Ltd, Karimnagar, Telangana, India for providing experimental facility to conduct the trial. Authors express thanks to Evonik Asia Pacific South, Singapore for analyzing the amino acids in feed ingredients and lysine in compounded feed.

\section{REFERENCES}

1. Meluzzi A, Sirri F, Tallarico N, Franchini A. Nitrogen retention and performance of brown laying hens on diets with different protein content and constant concentration of amino acids and energy. Br Poult Sci 2001;42:213-7. https://doi.org/ 10.1080/00071660120048474

2. Ayaşan T, Okan F. Effects of diets containing different levels of threonine and lysine aminoacids on fattening performance of broiler chicks. Suleyman Demirel Univ J Agric 2010;5:3643 
3. NRC. Nutrient requirements of poultry. 9th ed. Washington, DC, USA: National Academies Press; 1994.

4. Önol AG, Daskiran M, Cengiz O, Nazligul A, Sari M. Effects of dietary vitamin $\mathrm{E}$ and lysine supplementation on performance and egg shell quality parameters of heat stressed laying hens in early laying period. Kafkas Univ Vet Fak Derg 2012; 18:49-54.

5. Liu Z, Wu G, Bryant MM, Roland DA. Influence of added synthetic lysine in low-protein diets with the methionine plus cysteine to lysine ratio maintained at 0.75. J Appl Poult Res 2005;14:174-82. https://doi.org/10.1093/japr/14.1.174

6. Onimisi PA, Orunmuyi M, Musa AA, Bale S, Bawa GS. Effects of feed lysine content on laying performance and egg quality of late laying hens. Int J Appl Res Technol 2012;1:104-10.

7. Safaa HM, Serrano MP, Valencia DG, et al. Effects of the levels of methionine, linoleic acid, and added fat in the diet on productive performance and egg quality of brown laying hens in the late phase of production. Poult Sci 2008;87:1595602. https://doi.org/10.3382/ps.2008-00005

8. BV 300. Layer management guide. Pune, India: Venkateshwara Research and Breeding Farm; 2014.

9. Llames CR, Fontaine J. Determination of amino acids in feeds: collaborative study. J AOAC Int 1994;77:1262-402. https://doi. org/10.1093/jaoac/77.6.1362

10.Littell RC, Henry PR, Ammerman CB. Statistical analysis of repeated measures data using SAS procedures. J Anim Sci 1998;76:1216-31. https://doi.org/10.2527/1998.7641216x

11.SPSS. SPSS for Windows: release 11.5, standard version. Chicago, IL, USA: SPSS Inc.; 2002.

12. Pesti GM, Vedenov D, Cason JA, Billard L. A comparison of methods to estimate nutritional requirements from experimental data. Br Poult Sci 2009;50:16-32. https://doi.org/10. 1080/00071660802530639

13. Rama Rao SV, Paul SS, Raju M, Prakash B, Srilatha T. Effect of incremental levels of dietary total sulfur amino acids on performance of white leghorn laying hens fed diets containing guar (Cyamopsis tetragonoloba) meal. J Sci Food Agric 2019; 99:3086-96. https://doi.org/10.1002/jsfa.9522

14.Silva EP, Malheiros EB, Sakomura NK, et al. Lysine requirements of laying hens. Livest Sci 2015;173:69-77. https://doi. org/10.1016/j.livsci.2015.01.005

15. Ayaşan T, Okan F, Hizli H. Threonine requirement of broilers from 22 to 42 days. Int J Poult Sci 2009;8:862-5.

16. Bonekamp RPRT, Lemme A, Wijtten PJA, Sparla JKWM. Effects of amino acids on egg number and egg mass of brown (heavy breed) and white (light breed) laying hens. Poult Sci 2010;89:522-9. https://doi.org/10.3382/ps.2009-00342

17. Spangler H, Utterback P, Parsons CM, Tillman P. Determining the digestible lysine requirement of 22- to 47-week-old
Lohmann laying hens using an increasing protein titration methodology. Poult Sci 2019;98:1706-15. https://doi.org/ $10.3382 / \mathrm{ps} / \mathrm{pey} 503$

18. Rama Rao SV, Ravindran V, Srilatha T, Panda AK, Raju MVLN. Effect of dietary concentrations of energy, crude protein, lysine, and methionine on the performance of White Leghorn layers in the tropics. J Appl Poult Res 2011;20:52841. https://doi.org/10.3382/japr.2011-00355

19. Novak C, Yakout HM, Scheideler SE. The effect of dietary protein level and total sulfur amino acid:lysine ratio on egg production parameters and egg yield in Hy-Line W-98 hens. Poult Sci 2006;85:2195-206 https://doi.org/10.1093/ps/85. 12.2195

20.Santos TA, Geraldo A, Machado LC, Pelicia K, Simao SD, Filho JAV. Digestible lysine levels for laying hens and their effects on egg quality. Acta Sci 2014;36:41-7. https://doi.org/ 10.4025/actascianimsci.v36i1.21823

21.Pastore SM, Gomes PC, Viana GDS, et al. Standardized ileal digestible lysine requirement of white commercial layers in peak egg production. Biosci J 2018;34:186-93. https://doi. org/10.14393/BJ-v34n1a2018-37205

22.Kumari KNR, Reddy VR, Preetham VC, Kumar DS, Sen AR, Rama Rao SV. Effect of supplementation of crystalline lysine on the performance of WL layers in tropics during summer. Trop Anim Health Prod 2016;48:705-10. https:// doi.org/10.1007/s11250-016-1003-Z

23. Schutte JB, Smink W. Requirement of the laying hen for apparent fecal digestible lysine. Poult Sci 1998;77:697-701. https://doi.org/10.1093/ps/77.5.697

24. Novak C, Yakout H. Scheideler S. The combined effects of dietary lysine and total sulfur amino acid level on egg production parameters and egg components in Dekalb Delta laying hens. Poult Sci 2004;83:977-84. https://doi.org/10. 1093/ps/83.6.977

25.Harms RH, Russell GB. Performance of commercial laying hens fed diets with various levels of methionine. J Appl Poult Res 2003;12:449-55. https://doi.org/10.1093/japr/12.4.449

26. Sohail SS, Bryant MM, Roland DA. Influence of supplemental lysine, isoleucine, threonine, tryptophan and total sulfur amino acids on egg weight of Hy-line W-36 hens. Poult Sci 2002;81:1038-44. https://doi.org/10.1093/ps/81.7.1038

27.Ullah Z, Ahmed G, Nisa M, Sarwar M. Standardized ileal amino acid digestibility of commonly used feed ingredients in growing broilers. Asian-Australas J Anim Sci 2016;29:132230. https://doi.org/10.5713/ajas.15.0703

28. Russell GB, Harms RH. Tryptophan requirement of the commercial hen. Poult Sci 1999;78:1283-5. https://doi.org/10. 1093/ps/78.9.1283 